\title{
HERBICIDAS INIBIDORES DA ACCASE EM PLANTAS DE Cenchrus echinatus EM ESTRESSE HÍDRICO
}

\author{
ABSTRACT: ACCASE-INHIBITOR HERBICIDES IN PLANTS OF Cenchrus echinatus \\ IN WATER STRESS
}

\section{Maria Renata Rocha PEREIRA ${ }^{1}$; Guilherme Sasso F. de SOUZA² ;osé Iran Cardoso da Silva ${ }^{3}$; Dagoberto MARTINS ${ }^{4}$}

1. Engenheira Florestal, Professora, Doutora, Faculdade de Tecnologia de Capão Bonito - FATEC, Capão Bonito, SP, Brasil. mariarenatarp@ hotmail.com; 2. Engenheiro agrônomo, Doutorando, Departamento de Produção Vegetal, Faculdade de Ciências Agronômicas - FCA, Universidade Estadual Paulista - UNESP, Botucatu, SP, Brasil; 3. Engenheiro agrônomo, Pós Doutorando, Universidade Federal do Tocantins, Gurupi, TO, Brasil; 4. Engenheiro agrônomo, Professor Livre-Docente, Departamento de Produção Vegetal, Faculdade de Ciências Agrárias e Veterinária - FCAV - UNESP, Jaboticabal, SP, Brasil

RESUMO: Este projeto objetivou relacionar a eficiência de controle de herbicidas inibidores da ACCase aplicados em pós-emergência em plantas de Cenchrus echinatus submetidas a diferentes teores de água no solo. Os experimentos foram conduzidos em casa de vegetação, com a aplicação de três diferentes herbicidas (fluazifop-p-butil, haloxyfop-methyl e sethoxydim + óleo mineral Assist). O delineamento experimental utilizado para cada herbicida foi inteiramente casualizado, com 4 repetições, constituído de um fatorial 3 x 4, sendo a combinação de três manejos hídricos $(-0,03 ;-0,07$ e $-1,5 \mathrm{MPa})$ e quatro doses destes produtos $(100,50,25$ e $0 \%$ da dose recomendada). A aplicação dos herbicidas foi efetuada no estádio vegetativo de 2-3 perfilhos. Os manejos hídricos foram iniciados no estádio de desenvolvimento de duas folhas, repondo-se a água até o solo atingir o potencial de -0,01 MPa, quando este chegasse à tensão pré-determinada para cada manejo hídrico. As avaliações visuais de fitotoxicidade foram realizadas aos $7,14,21$ e 28 dias após a aplicação e a matéria seca das plantas ao final destas. A eficiência de controle dos diferentes herbicidas foi influenciada pelos manejos hídricos sendo menor em plantas mantidas em potencial mínimo de água no solo de -1,5 MPa. Todos os herbicidas testados apresentaram controles insatisfatórios em aplicações tardias (plantas com 2-3 perfilhos).

PALAVRAS-CHAVE: Capim-carrapicho. Controle químico. Restrição hídrica. Planta daninha.

\section{INTRODUÇÃO}

A espécie Cenchrus echinatus é uma gramínea altamente competitiva com as culturas em água, nutrientes e luz. Invadem culturas de algodão, amendoim, arroz de sequeiro, café, cana-de-açúcar, feijão, frutíferas, fumo, mandioca, milho, pastagem, soja e sorgo. Também é indicadora de campos agrícolas muito decaídos, erodidos e adensados, surgindo em pastagens onde o pisoteio foi intenso. (SANTOS, 2007).

Conhecida popularmente por capimcarrapicho ou timbete, é uma gramínea herbácea de ocorrência bastante generalizada em todo o Brasil, sendo considerada uma das seis espécies mais agressivas na agricultura moderna (PACHECO e MARINIS, 1984). É uma das plantas de maior dificuldade de controle na cultura do sorgo (ABIT et al., 2009), e do milheto, além de cultivos de verão e de "safrinha" (DUARTE et al., 2007) constituindose num grande problema na região dos cerrados, devido à limitada disponibilidade de herbicidas com ação graminicida registrados e que apresentam seletividade para essas culturas (DAN, et al., 2011).

O grau de interferência de acordo com Carvalho e Guzzo (2008) destas com as plantas cultivadas dependem de diversos fatores relacionados à comunidade infestante (composição específica, densidade e distribuição) e à própria cultura (gênero, espécie ou cultivar, espaçamento entre sulcos e densidade de semeadura).

As plantas daninhas, geralmente, são mais eficientes que as culturas agrícolas no uso da água, independentemente do seu sistema de fotossíntese e, por isto, quando a água é escassa, as culturas são mais afetadas. Segundo Patterson (1995), o estresse hídrico ou disponibilidade de água podem influenciar na duração do período crítico livre das plantas daninhas para várias culturas.

De acordo com Pitelli e Pitelli (2004), normalmente, as plantas que apresentam o metabolismo fotossintético $\mathrm{C} 4$ são mais eficientes e experimentam menores reduções de crescimento quando a competição por água é intensificada, sendo mais severa entre plantas daninhas $\mathrm{C}_{4}$ e uma cultura $\mathrm{C}_{3}$. Há relatos de perdas de até $50 \%$ na produção de arroz em terras altas, cujas necessidades hídricas são satisfeitas apenas pelas precipitações pluviais ou, de forma suplementar, com irrigação por aspersão.

A maioria dos estresses ambientais como o aumento da intensidade luminosa e baixa umidade do solo pode induzir a uma mudança na composição e estrutura das folhas, e estas mudanças podem influenciar posteriormente à penetração, absorção e 
translocação dos herbicidas, pois tendem a induzir a um aumento de pilosidade, estômatos afundados na epiderme, aumento do numero de células buliformes envolvidas no mecanismo de enrolamento e desenrolamento das folhas e síntese de cutícula, com um consequente aumento do caráter lipofílico da superfície foliar. A umidade relativa do ar tem também um papel importante na hidratação da cutícula e na redissolução de sais de herbicidas na superfície foliar (ROMAN et al. 2005/2).

A influência de fatores do ambiente como o estresse hídrico na atividade de herbicidas relacionase principalmente com as mudanças morfológicas impostas às plantas pelo ambiente. Plantas em estresse hídrico podem ter cutículas desidratadas, o que pode reduzir a absorção de herbicidas, resultando, assim, em uma possível menor fitotoxicidade à cultura e uma menor eficiência do produto no controle da planta daninha (PEREGORY et al. 1990).

Para melhor entender a relação da água disponível no solo para as plantas com o desempenho dos herbicidas estudados, é necessário o conhecimento e determinação de qual o menor teor de água do solo que não prejudica a ação de cada produto no controle desta espécie.

O objetivo deste trabalho foi relacionar a eficiência de controle de herbicidas inibidores da ACCase, aplicados em pós-emergência, em plantas de $C$. echinatus quando submetidas a estresse hídrico, determinando qual potencial de água no solo que pode prejudicar a eficiência de controle dos herbicidas e se há diferenças entre as moléculas testadas.

\section{MATERIAL E MÉTODOS}

O experimento foi instalado e conduzido no Departamento de Produção Vegetal, Setor Agricultura, da Faculdade de Ciências Agronômicas, UNESP, no município de Botucatu São Paulo, cujas coordenadas geográficas são $22^{\circ} 51^{\prime} 03$ ' ' de latitude sul e $48^{\circ} 25^{\prime} 37^{\prime}$ ' de longitude oeste de Greenwich, com altitude de $786 \mathrm{~m}$, nos meses de novembro de 2008 a janeiro de 2009, com as seguintes caracterizações climáticas nesse período dentro da casa de vegetação (médias): temperatura mínima de $19,8^{\circ} \mathrm{C}$, temperatura máxima de $29,8{ }^{\circ} \mathrm{C}$, umidade relativa do ar de $77,8 \%$ e evapotranspiração $3,1 \mathrm{~mm} \mathrm{mês}^{-1}$, a qual foi monitorada diariamente através de um Tanque Classe A.

A espécie utilizada foi Cenchrus echinatus, cultivadas em vasos plásticos de $2 \mathrm{~L}$, contendo solo de descrição textural classificada como média por meio da análise granulométrica $(65,6 \%$ de areia, 6,7 de silte, 27,7 de argila). Foi realizada adubação do solo de acordo com análise química (Tabela 1).

Tabela 1. Análise química do solo utilizado nos estudos. Botucatu/SP. 2008/2009.

\begin{tabular}{|c|c|c|c|c|c|c|c|c|c|}
\hline \multirow{2}{*}{$\underset{\mathrm{CaCl}_{2}}{\mathbf{p H}}$} & \multirow{2}{*}{$\begin{array}{c}\text { M.O } \\
\mathrm{g} \mathrm{dm}^{-3}\end{array}$} & \multirow{2}{*}{$\begin{array}{l}P \text { resina } \\
\mathrm{mg} \mathrm{dm}^{-3}\end{array}$} & \multicolumn{6}{|c|}{$\mathbf{m m o l}_{\mathrm{c}} \mathbf{d m}^{-3}$} & \multirow{2}{*}{$\underset{(\%)}{V}$} \\
\hline & & & $\mathrm{H}+\mathbf{A l}$ & K & $\mathbf{C a}$ & $\mathbf{M g}$ & $\mathbf{S B}$ & CTC & \\
\hline 4,6 & 7 & 3 & 22 & 0,2 & 2 & 2 & 4 & 26 & 15 \\
\hline
\end{tabular}

O solo, antes da semeadura, foi seco ao ar e revolvido duas vezes por semana até umidade constante de 3\%. Para obtenção da curva de retenção de água, foi utilizada a placa de pressão de Richards (Klar, 1984). A partir dos resultados da curva de retenção, foram estabelecidos três potenciais mínimos de água $\left(\Psi_{\mathrm{s}}\right)$ : $-0,03 \mathrm{MPa}$, $0,07 \mathrm{MPa}$ e $-1,5 \mathrm{MPa}$, sendo $13 \%, 10 \%$ e $8 \%$ de umidade do solo, respectivamente, compondo os manejos hídricos, avaliados por meio de pesagem dos vasos. Ao atingir as imediações do potencial definido para cada tratamento, foi feita reposição da água evapotranspirada até alcançar a massa do potencial de água máximo de retenção de água do solo (-0,01 MPa, equivalente a $14 \%$ de umidade do solo). Os manejos hídricos foram iniciados no estádio de desenvolvimento de duas folhas em cada planta.
Para garantir a efetivação do processo de germinação e o desenvolvimento das plântulas, o solo foi previamente irrigado até que a umidade atingisse a capacidade de campo, de forma a garantir a efetivação do processo de germinação e o desenvolvimento das plântulas. Após a emergência das plântulas foi efetuado um desbaste, deixando duas plântulas por vaso.

Foi utilizado um pulverizador costal, equipado com barra de aplicação contendo quatro pontas de pulverização tipo jato plano XR11002VS, com um consumo de calda de $200 \mathrm{~L} \mathrm{ha}^{-1}$.

A aplicação dos herbicidas foi realizada na fase de desenvolvimento de 2-3 perfilhos das plantas daninhas. Foram aplicados separadamente três diferentes herbicidas (fluazifop-p-butil, haloxyfop-methyl e sethoxydim + óleo mineral Assist), sendo o delineamento experimental utilizado para cada produto inteiramente 
casualizado, com quatro repetições, constituído de um fatorial $3 \times 4$, sendo a combinação dos três manejos hídricos $(-0,03,-0,07$ e $-1,5 \mathrm{MPa})$ e quatro doses desses produtos $(100,50,25$ e $0 \%$ da dose recomendada). De acordo com os fabricantes de cada produto, $100 \%$ da dose recomendada de cada herbicida, expressa em gramas de ingrediente ativo por hectare, é de: sethoxydim: 184; haloxyfopmethyl: 60; e fluazifop-p-butil: 125 , (g i.a. ha $\left.{ }^{-1}\right)$.

Os efeitos dos tratamentos sobre as plantas foram avaliados visualmente aos 7, 14, 21 e 28 dias após aplicação, por meio de uma escala percentual de notas, na qual " 0 " consiste em ausência de injúria e "100" em morte das plantas (SBCPD, 1995). Ao final das avaliações, as plantas foram coletadas e secas em estufa de ventilação forçada de ar a $60^{\circ} \mathrm{C}$ até atingir peso constante; em seguida, foi determinada a massa seca das amostras.

O delineamento experimental utilizado nos estudos foi o inteiramente casualizado, com quatro repetições. Os resultados de fitointoxicação foram submetidos à análise de variância pelo teste $\mathrm{F}$, e as massas secas de plantas foram submetidas aos modelos de regressão linear e polinomial, sendo as médias dos tratamentos comparadas pelo de teste Tukey a $5 \%$.

\section{RESULTADOS E DISCUSSÃO}

Os sintomas de fitotoxicidade foram nulos aos 7 DAA independentes do herbicida, dose e manejo hídrico utilizado. Nas Tabelas 2,3 e 4 encontram-se as avaliações realizadas aos 14 DAA em plantas com aplicação dos produtos, que provocaram sintomas mais visíveis como amarelecimento das folhas mais jovens. Nas plantas mantidas em solo com tensão mínima de $-0,03 \mathrm{MPa}$, não se observaram diferenças nos resultados provocados pelos herbicidas fluazifop-p-butil e haloxyfop-methyl, sendo em média de 21,25\%. Em plantas submentidas a este mesmo manejo hídrico, o herbicida sethoxydim (Tabela 4) provocou a maior fitotoxicidade $(38,75 \%)$, na aplicação de $100 \%$ da dose recomendada. Também, não se registrou diferenças no controle nas plantas mantidas em solo com tensão mínima de $-0,07 \mathrm{MPa}$, para os três produtos estudados, sendo a fitotoxicidade em média de 24,3\%. Com a utilização do manejo hídrico de -1,5 $\mathrm{MPa}$, os resultados obtidos com o herbicida sethoxydim foram mais satisfatórios em comparação aos demais, sendo de $18,75 \%$ e, os mais baixos foram provocados pelo haloxyfop-methyl, que não alcançou $6 \%$ de controle.

Com a redução da dose para $1 / 2$ da recomendada, não houve redução significativa do controle com o uso do herbicida fluazifop-p-butil, em todos os manejos hídricos utilizados (Tabela 2). Fato este, também observado com a aplicação do herbicida haloxyfop-methyl (Tabela 3), com exceção dos tratamentos com manejo hídrico de 0,07 $\mathrm{MPa}$, em que a redução dos sintomas de fitotoxicidade foram de 53\%. Porém, com a aplicação do herbicida sethoxydim observaram-se reduções no controle de $30 \%$ e $58 \%$, em plantas mantidas em solos com tensões mínimas de $-0,03$ e 1,5 $\mathrm{MPa}$, respectivamente.

Tabela 2. Porcentagem de controle em plantas de C. echinatus no estádio de 2-3 perfilhos submetidas a diferentes manejos hídricos, 14 dias após aplicação do herbicida fluazifop-p-butil. Botucatu/SP, 2008/2009.

\begin{tabular}{|c|c|c|c|c|}
\hline \multirow{2}{*}{$\begin{array}{l}\text { Manejo Hídrico } \\
\text { (MPa) }\end{array}$} & \multicolumn{4}{|c|}{$\%$ da dose de herbicida } \\
\hline & 0 & 25 & 50 & 100 \\
\hline$-0,03$ & 0,00 a B & 16,25 a A & 19,00 a A & 22,00 a $\mathrm{A}$ \\
\hline$-0,07$ & 0,00 a C & 13,75 a $\mathrm{B}$ & 16,75 ab AB & 21,25 a A \\
\hline$-1,5$ & 0,00 a B & 3,50 b. B & 11,25 b. A & 13,50 b A \\
\hline $\mathrm{F}_{\text {Manejo Hídrico }}(\mathrm{M})$ & \multicolumn{4}{|c|}{$17,511 * *$} \\
\hline $\mathrm{F}_{\text {dose }}(\mathrm{D})$ & \multicolumn{4}{|c|}{$60,438 * *$} \\
\hline$F(M) \times(D)$ & \multicolumn{4}{|c|}{$2,399 * *$} \\
\hline $\mathrm{CV}(\%)$ & \multicolumn{4}{|c|}{32,2} \\
\hline
\end{tabular}

Médias seguidas de mesma letra minúscula na coluna e maiúscula na linha, não diferem entre si pelo teste de Tukey ( $>>0,05) ; * *$ - valor significativo pelo teste " $F$ " $(p \leq 0,01)$.

A aplicação de $1 / 4$ da dose do herbicida fluazifop-p-butil também não reduziu a eficiência de controle do produto, comparando-se com as aplicações de 100 e $50 \%$ da dose recomendada, com exceção das aplicações em plantas submetidas a regime hídrico de $-1,5 \mathrm{MPa}$, nas quais os sintomas 
de fitotoxicidade foram muito discretos. Os resultados das aplicações com doses reduzidas do herbicida haloxyfop-methyl em plantas submetidas a estresse hídrico (manejo hídrico de $-1,5 \mathrm{MPa}$ ) foram semelhantes. As reduções mais evidentes de controle ocorreram com o herbicida sethoxydim, que foi de $70 \%$ em comparação com aplicação de $100 \%$ da dose, em plantas mantidas em solo com tensões mínimas de $-0,03$ e - $0,07 \mathrm{MPa}$ e de $78 \%$ em plantas com severa restrição hídrica (manejo hídrico de -1,5 MPa).

Tabela 3. Porcentagem de controle em plantas de C. echinatus no estádio de 2-3 perfilhos submetidas a diferentes manejos hídricos, 14 dias após aplicação do herbicida haloxyfop-methyl. Botucatu/SP, 2008/2009.

\begin{tabular}{|c|c|c|c|c|}
\hline \multirow{2}{*}{$\begin{array}{c}\text { Manejo Hídrico } \\
\text { (MPa) }\end{array}$} & \multicolumn{4}{|c|}{$\%$ da dose de herbicida } \\
\hline & $\mathbf{0}$ & 25 & 50 & 100 \\
\hline$-\mathbf{0 , 0 3}$ & 0,00 a B & 4,50 a B & 14,50 a $\mathrm{A}$ & 20,50 a $\mathrm{A}$ \\
\hline$-0,07$ & 0,00 a C & 7,25 a BC & 11,25 a B & 24,25 a A \\
\hline$-1,5$ & $0,00 \_$a $\mathrm{C}$ & 4,00 a BC. & 7,75 b B & 18,75 a A \\
\hline $\mathrm{F}_{\text {Manejo Hídrico }}(\mathrm{M})$ & \multicolumn{4}{|c|}{$2,691^{\mathrm{ns}}$} \\
\hline $\mathrm{F}_{\text {dose }}(\mathrm{D})$ & \multicolumn{4}{|c|}{$66,062 * *$} \\
\hline $\mathrm{F}(\mathrm{M}) \times(\mathrm{D})$ & \multicolumn{4}{|c|}{$1,095^{\mathrm{ns}}$} \\
\hline $\mathrm{CV}(\%)$ & \multicolumn{4}{|c|}{41,2} \\
\hline
\end{tabular}

Médias seguidas de mesma letra minúscula na coluna e maiúscula na linha, não diferem entre si pelo teste de Tukey $(\mathrm{p}>0,05) ; * *$ - valor significativo pelo teste " $\mathrm{F}$ " $(\mathrm{p} \leq 0,01)$.

Tabela 4. Porcentagem de controle em plantas de $C$. echinatus no estádio de 2-3 perfilhos submetidas a diferentes manejos hídricos, 14 dias após aplicação do herbicida sethoxydim. Botucatu/SP, 2008/2009.

\begin{tabular}{|c|c|c|c|c|}
\hline \multirow{2}{*}{$\begin{array}{c}\text { Manejo Hídrico } \\
\text { (MPa) }\end{array}$} & \multicolumn{4}{|c|}{ \% da dose de herbicida } \\
\hline & 0 & 25 & 50 & 100 \\
\hline$-0,03$ & 0,00 a C & 11,50 a C & 26,25 a B & 38,75 a A \\
\hline$-0,07$ & 0,00 a $B$ & 8,25 a $\mathrm{B}$ & 21,25 a $A$ & 27,50 b A \\
\hline$-1,5$ & 0,00 a B & 4,00 a B & 7,75 b AB & $18,75 \mathrm{~b} A$ \\
\hline $\mathrm{F}_{\text {Manejo Hídrico }}(\mathrm{M})$ & \multicolumn{4}{|c|}{$13,360 * *$} \\
\hline $\mathrm{F}_{\text {dose }}(\mathrm{D})$ & \multicolumn{4}{|c|}{$45,863 * *$} \\
\hline $\mathrm{F}(\mathrm{M}) \times(\mathrm{D})$ & \multicolumn{4}{|c|}{$2,439 *$} \\
\hline $\mathrm{CV}(\%)$ & \multicolumn{4}{|c|}{46,2} \\
\hline
\end{tabular}

Médias seguidas de mesma letra minúscula na coluna e maiúscula na linha, não diferem entre si pelo teste de Tukey ( $>0,05) ; * *$ - valor significativo pelo teste " $F$ " $(p \leq 0,01)$.

Nas Tabelas 5, 6 e 7 estão apresentados os resultados das avaliações realizadas aos 21 DAA, em que não se nota diferenças dos resultados de fitotoxicidade entre as aplicações de $100 \%$ da dose recomendada de todos os produtos em plantas sem restrição hídrica (manejo hídrico de -0,03 $\mathrm{MPa}$ ), o que também foi verificado nos tratamentos em plantas submetidas a manejo hídrico de -0,07 e -1,5 MPa.

A redução em $50 \%$ das doses do herbicida sethoxydim (Tabela 7) e fluazifop-p-butil (Tabela 5) não reduziram a eficiência de controle destes sobre as plantas mantidas em solos com tensões mínimas de -0,03 e -0,07 MPa. Observou-se diminuição do controle apenas em plantas sob estresse hídrico (manejo hídrico de -1,5 MPa) com o uso do herbicida sethoxydim, que foi de até $60 \%$. Já, as plantas com aplicação do herbicida fluazifop-pbutil, mantidas neste mesmo manejo hídrico, atingiu $23,2 \%$ de controle. Este fato contrário pode ser explicado devido, talvez, à alta debilidade das plantas mantidas sob estresse hídrico.

Os sintomas de injúrias provocados pelo herbicida haloxyfop-methyl (Tabela 6) em plantas sem restrição hídrica acompanharam a redução da dose do mesmo, diminuindo em 60\%. Já, em plantas 
com manejo hídrico de $-0,07$ e $-1,5 \mathrm{MPa}$ não se observou diferenças.

Não se registrou diferenças nos sintomas de fitotoxicidade com a aplicação de $25 \%$ da dose dos herbicidas em todos os manejos utilizados, com exceção da aplicação do herbicida haloxyfop-methyl (que apresentou os menores valores de controle em todos os tratamentos), sendo os sintomas praticamente imperceptíveis em plantas mantidas com tensão mínima de -1,5 MPa de água no solo.

Tabela 5. Porcentagem de controle em plantas de $C$. echinatus submetidas a diferentes manejos hídricos, 21 dias após aplicação do herbicida fluazifop-p-butil. Botucatu/SP, 2008/2009.

\begin{tabular}{|c|c|c|c|c|}
\hline \multirow{2}{*}{$\begin{array}{c}\text { Manejo Hídrico } \\
\text { (MPa) }\end{array}$} & \multicolumn{4}{|c|}{$\%$ da dose de herbicida } \\
\hline & $\mathbf{0}$ & 25 & $\mathbf{5 0}$ & 100 \\
\hline$-0,03$ & 0,00 a $B$ & 23,75 a A & 30,25 a $\mathrm{A}$ & 40,75 a A \\
\hline$-0,07$ & 0,00 a C & $11,50 \mathrm{ab} \mathrm{BC}$ & 22,00 a B & 40,00 a A \\
\hline$-1,5$ & 0,00 a B & 6,75 b $\mathrm{AB}$ & 23,25 a $\mathrm{AB}$ & $17,00 \mathrm{~b} A$ \\
\hline $\mathrm{F}_{\text {Manejo Hídrico }}(\mathrm{M})$ & \multicolumn{4}{|c|}{$7,122 * *$} \\
\hline $\mathrm{F}_{\text {dose }}(\mathrm{D})$ & \multicolumn{4}{|c|}{$30,068 * *$} \\
\hline $\mathrm{F}(\mathrm{M}) \times(\mathrm{D})$ & \multicolumn{4}{|c|}{$2,255^{\mathrm{ns}}$} \\
\hline $\mathrm{CV}(\%)$ & \\
\hline
\end{tabular}

Médias seguidas de mesma letra minúscula na coluna e maiúscula na linha, não diferem entre si pelo teste de Tukey $(\mathrm{p}>0,05) ; * *$ - valor significativo pelo teste " $\mathrm{F}$ " $(\mathrm{p} \leq 0,01)$.

Tabela 6. Porcentagem de controle em plantas de $C$. echinatus submetidas a diferentes manejos hídricos, 21 dias após aplicação do herbicida haloxyfop-methyl. Botucatu/SP, 2008/2009.

\begin{tabular}{|c|c|c|c|c|}
\hline \multirow{2}{*}{$\begin{array}{c}\text { Manejo Hídrico } \\
\text { (MPa) }\end{array}$} & \multicolumn{4}{|c|}{$\%$ da dose de herbicida } \\
\hline & $\mathbf{0}$ & 25 & 50 & 100 \\
\hline$-\mathbf{0 , 0 3}$ & 0,00 a $\mathrm{B}$ & 6,75 a $\mathrm{B}$ & 18,25 a B & 47,25 a $A$ \\
\hline$-0,07$ & 0,00 a B & 3,00 a $B$ & 12,50 a $A B$ & 24,50 a A \\
\hline$-1,5$ & 0,00 a B & 7,75. a B & 10,75 a $\mathrm{AB}$ & 26,75 a A \\
\hline $\mathrm{F}_{\text {Manejo Hídrico }}(\mathrm{M})$ & \multicolumn{4}{|c|}{$3,041^{\mathrm{ns}}$} \\
\hline $\mathrm{F}_{\text {dose }}(\mathrm{D})$ & \multicolumn{4}{|c|}{$24,959 * *$} \\
\hline$F(M) \times(D)$ & \multicolumn{4}{|c|}{$1,408^{\mathrm{ns}}$} \\
\hline $\mathrm{CV}(\%)$ & \multicolumn{4}{|c|}{75,6} \\
\hline
\end{tabular}

Médias seguidas de mesma letra minúscula na coluna e maiúscula na linha, não diferem entre si pelo teste de Tukey $(p>0,05) ; * *$ - valor significativo pelo teste " $F$ " $(p \leq 0,01)$.

Tabela 7. Porcentagem de controle em plantas de $C$. echinatus submetidas a diferentes manejos hídricos, 21 dias após aplicação do herbicida sethoxydim. Botucatu/SP, 2008/2009.

\begin{tabular}{|c|c|c|c|c|}
\hline \multirow{2}{*}{$\begin{array}{c}\text { Manejo Hídrico } \\
\text { (MPa) }\end{array}$} & \multicolumn{4}{|c|}{$\%$ da dose de herbicida } \\
\hline & $\mathbf{0}$ & 25 & 50 & 100 \\
\hline$-\mathbf{0 , 0 3}$ & 0,00 a $\mathrm{B}$ & 12,50 a B & 44,50 a $\mathrm{A}$ & 51,75 a A \\
\hline$-\mathbf{0 , 0 7}$ & 0,00 a $\mathrm{B}$ & 11,75 a $\mathrm{AB}$ & 23,50 b A & 29,25 b A \\
\hline$-1,5$ & 0,00 a $\mathrm{B}$ & 7,75 а $\mathrm{AB}$ & 10,75 a $\mathrm{AB}$ & $26,75 \mathrm{~b} A$ \\
\hline $\mathrm{F}_{\text {Manejo Hídrico }}(\mathrm{M})$ & \multicolumn{4}{|c|}{$10,195^{* *}$} \\
\hline $\mathrm{F}_{\text {dose }}(\mathrm{D})$ & \multicolumn{4}{|c|}{$29,491 * *$} \\
\hline $\mathrm{F}(\mathrm{M}) \times(\mathrm{D})$ & \multicolumn{4}{|c|}{$2,840 *$} \\
\hline $\mathrm{CV}(\%)$ & \multicolumn{4}{|c|}{56,0} \\
\hline
\end{tabular}

Médias seguidas de mesma letra minúscula na coluna e maiúscula na linha, não diferem entre si pelo teste de Tukey $(\mathrm{p}>0,05) ; * *$ - valor significativo pelo teste " $F$ " $(\mathrm{p} \leq 0,01)$. 
Ao final das avaliações aos 28 DAA, nenhum herbicida proporcionou controle total desta espécie de planta daninha conforme demonstrado nas Tabelas 8, 9 e 10. Não houve diferenças de fitotoxicidade nas aplicações de $100 \%$ da dose recomendada dos três produtos químicos, atingindo em média $82,9 \%$ de controle, em plantas sem estresse hídrico.

Em relação às plantas mantidas em solo com tensão mínima de $-0,07 \mathrm{MPa}$, as maiores porcentagens de controle foram resultantes da aplicação do herbicida fluazifop-p-butil, atingindo $73,2 \%$ (Tabela 8). Os outros dois herbicidas provocaram em média $63,75 \%$ de controle. Não se observou diferenças dos resultados de fitotoxicidade nas plantas mantidas sob restrição hídrica (manejo hídrico de -1,5 $\mathrm{MPa}$ ), em média de $55 \%$, bem como também não se verificou diferenças destas com as plantas mantidas em solos com tensão mínima de 0,07 MPa.

Resultados semelhantes foram encontrados por Pereira et al., (2012a) com aplicação de herbicidas com ação graminicida em plantas de Urochloa decumbens, em que a eficiência de controle foi menor em plantas mantidas potencial de água no solo de $-1,5 \mathrm{MPa}$, em estádios de desenvolvimento inicial e tardio.

Tabela 8. Porcentagem de controle em plantas de C. echinatus submetidas a diferentes manejos hídricos, 28 dias após aplicação do herbicida fluazifop-p-butil. Botucatu/SP, 2008/2009.

\begin{tabular}{|c|c|c|c|c|c|}
\hline \multirow{2}{*}{$\begin{array}{c}\text { Manejo Hídrico } \\
\text { (MPa) }\end{array}$} & \multicolumn{5}{|c|}{$\%$ da dose de herbicida } \\
\hline & $\mathbf{0}$ & 25 & & $\mathbf{5 0}$ & 100 \\
\hline$-\mathbf{0 , 0 3}$ & 0,00 a D & 45,75 & a $\mathrm{C}$ & 63,25 a B & 80,25 a A \\
\hline$-0,07$ & 0,00 a C & 44,50 & a B & 64,50 a A & 73,25 a A \\
\hline$-1,5$ & 0,00 a B & 3,00 & b B & 59,75 a A & 60,00 b A \\
\hline $\mathrm{F}_{\text {Manejo Hídrico }}(\mathrm{M})$ & \multicolumn{5}{|c|}{$25,847 * *$} \\
\hline $\mathrm{F}_{\text {dose }}(\mathrm{D})$ & \multicolumn{5}{|c|}{$244,018 * *$} \\
\hline$F(M) \times(D)$ & \multicolumn{5}{|c|}{$9,548 * *$} \\
\hline $\mathrm{CV}(\%)$ & \multicolumn{5}{|c|}{17,5} \\
\hline
\end{tabular}

Médias seguidas de mesma letra minúscula na coluna e maiúscula na linha, não diferem entre si pelo teste de Tukey $(\mathrm{p}>0,05) ; * *$ - valor significativo pelo teste " $\mathrm{F}$ " $(\mathrm{p} \leq 0,01)$.

Com a redução da dose recomendada dos herbicidas em $50 \%$, não se verificou diferenças nos resultados de fitotoxicidade com a aplicação dos herbicidas sethoxydim e fluazifop-p-butil, atingindo em média 62\%, independentemente do manejo hídrico estabelecido. A diferença nos resultados foi observada com a aplicação do herbicida haloxyfopmethyl (Tabela 9) em plantas nos diferentes manejos hídricos, atingindo $72,5 \%$ de controle em plantas sem estresse hídrico (manejo hídrico de 0,03 MPa), 42,75\% em plantas mantidas em solo com tensão mínima de $-0,07 \mathrm{MPa}$ de umidade e $20 \%$ em plantas submetidas a estresse hídrico severo (manejo hídrico de -1,5 MPa), sendo que com manejo hídrico de $-0,03 \mathrm{MPa}$, não se notou diferenças entre as aplicações dos três herbicidas.

Tabela 9. Porcentagem de controle em plantas de C. echinatus submetidas a diferentes manejos hídricos, 28 dias após aplicação do herbicida haloxyfop-methyl. Botucatu/SP, 2008/2009.

\begin{tabular}{|c|c|c|c|c|c|}
\hline \multirow{2}{*}{$\begin{array}{l}\text { Manejo Hídrico } \\
\text { (MPa) }\end{array}$} & \multicolumn{5}{|c|}{$\%$ da dose de herbicida } \\
\hline & 0 & 25 & & $\mathbf{5 0}$ & 100 \\
\hline$-0,03$ & 0,00 a $\mathrm{C}$ & 5,00 & $\mathrm{bCC}$ & 72,50 a $B$ & 90,00 a $A$ \\
\hline$-0,07$ & 0,00 a C & 2,75 & b C & 42,75 b B & 59,50 b A \\
\hline$-1,5$ & $0,00 \_$a $\mathrm{C}$ & 29,50 & a B & 64,00_a A & 64,00 b A \\
\hline $\mathrm{F}_{\text {Manejo Hídrico }}(\mathrm{M})$ & \multicolumn{5}{|c|}{$20,908 * *$} \\
\hline $\mathrm{F}_{\text {dose }}(\mathrm{D})$ & \multirow{2}{*}{\multicolumn{5}{|c|}{$\begin{array}{c}269,775^{* *} \\
10,691 * *\end{array}$}} \\
\hline$F(M) \times(D)$ & & & & & \\
\hline $\mathrm{CV}(\%)$ & \multicolumn{5}{|c|}{20,6} \\
\hline
\end{tabular}

Médias seguidas de mesma letra minúscula na coluna e maiúscula na linha, não diferem entre si pelo teste de Tukey $(p>0,05) ; * *$ - valor significativo pelo teste " $F$ " $(p \leq 0,01)$. 
A aplicação de doses fracionadas de haloxyfop-methyl, em plantas de U. decumbens, também reduziu a eficácia de herbicidas, em plantas com e sem estresse hídrico. Já, a aplicação de 50\% da dose recomendada dos herbicidas sethoxydim e fluazifop-p-butil, em plantas com 4-6 folhas em condições normais da água, não teve o controle prejudicado (PEREIRA et al., 2012a).

A redução da dose recomendada do herbicida sethoxydim (Tabela 10) para $1 / 4$ não diminuiu os efeitos de toxidez nas plantas mantidas em solos com tensões mínimas de -0,03 e - $-0,07 \mathrm{MPa}$ em relação à utilização de $1 / 2$ da dose deste mesmo produto. Contudo, em plantas mantidas em solo com tensão mínima de -1,5 MPa observou-se diminuição de mais de $50 \%$ no controle.
Estudos de Vallotton et al. (2003) corroboram estes resultados ora encontrados, em que plantas mantidas em solos com boa disponibilidade de água foram mais sensíveis aos herbicidas que aquelas plantas cultivadas sob estresse hídrico severo. Em aplicações tardias (2-3 perfilhos) o manejo hídrico influenciou a eficiência dos herbicidas sobre plantas de Digitaria horizontalis, pois as cultivadas sob estresse hídrico apresentaram menor fitotoxicidade (PEREIRA et al., 2012b). Estes resultados foram coerentes com a literatura que relata que normalmente há redução do desempenho do herbicida nas plantas sob estresse hídrico (BOYDSTON, 1992; PEREIRA et al., 2010; PEREIRA et al., 2012a).

Tabela 10. Porcentagem de controle em plantas de C. echinatus submetidas a diferentes manejos hídricos, 28 dias após aplicação do herbicida sethoxydim. Botucatu/SP, 2008/2009.

\begin{tabular}{|c|c|c|c|c|}
\hline \multirow{2}{*}{$\begin{array}{c}\text { Manejo Hídrico } \\
\text { (MPa) }\end{array}$} & \multicolumn{4}{|c|}{$\%$ da dose de herbicida } \\
\hline & $\mathbf{0}$ & 25 & 50 & 100 \\
\hline$-0,03$ & 0,00 a $\mathrm{C}$ & 57,50 a $\mathrm{B}$ & 62,50 a B & 78,50 a $\mathrm{A}$ \\
\hline$-0,07$ & 0,00 a $\mathrm{C}$ & 53,75 a $\mathrm{B}$ & 58,75 a $\mathrm{AB}$ & $68,25 \mathrm{~b} \mathrm{~A}$ \\
\hline$-1,5$ & 0,00 a $\mathrm{C}$ & $29,50 \mathrm{bB}$ & 64,00 a A & $64,75 \mathrm{~b}$ A \\
\hline $\mathrm{F}_{\text {Manejo Hídrico }}(\mathrm{M})$ & \multicolumn{4}{|c|}{$15,468 * *$} \\
\hline $\mathrm{F}_{\text {dose }}(\mathrm{D})$ & \multicolumn{4}{|c|}{$449,990 * *$} \\
\hline $\mathrm{F}(\mathrm{M}) \times(\mathrm{D})$ & \multicolumn{4}{|c|}{$9,512 * *$} \\
\hline $\mathrm{CV}(\%)$ & \multicolumn{4}{|c|}{11,5} \\
\hline
\end{tabular}

Médias seguidas de mesma letra minúscula na coluna e maiúscula na linha, não diferem entre si pelo teste de Tukey $(\mathrm{p}>0,05) ; * *$ - valor significativo pelo teste " $F$ " $(\mathrm{p} \leq 0,01)$.

Os resultados obtidos com a aplicação do herbicida haloxyfop-methyl (Tabela 9) permaneceram baixos em plantas sob manejo hídrico de -0,03 e -0,07 MPa, como em todas as avaliações anteriores, em média $3,25 \%$. Fato este, também observado nas aplicações do herbicida fluazifop-p-butil (Tabela 8), em plantas mantidas em solo com tensão mínima de -1,5 MPa. Contudo, observou-se uma redução de 43 e $39 \%$ no controle, com a aplicação de $1 / 4$ da dose deste herbicida em plantas mantidas em solo com tensões mínimas de 0,03 e $-0,07 \mathrm{MPa}$, respectivamente.

Pode-se inferir que esta espécie não é controlada satisfatoriamente pelos produtos utilizados neste estudo em aplicações tardias (2-3 perfilhos). Os melhores resultados, ou seja, maiores fitotoxicidade, foram obtidos nas aplicações em plantas sem estresse hídrico, não diferindo em muitos casos dos resultados em plantas mantidas em solo com tensão mínima de -0,07 MPa.

Conforme descrito por Dan et al. (2011), as aplicações de atrazine realizadas em pós-emergência nos estádios iniciais de desenvolvimento apresentam maior efeito supressor (controle superior a 90\%) sobre $C$. echinatus, porém as aplicações em plantas em estádios mais avançados de desenvolvimento apresentaram baixa eficiência de controle não superando a 50\%, corroborando os resultados apresentados neste trabalho para todos os herbicidas aplicados em plantas sob estresse hídrico. De acordo com o mesmo autor o controle satisfatório não foi alcançado devido ao grau de tolerância que a espécie adquire progressivamente. Esse aumento na tolerância aos herbicidas por gramíneas relaciona-se à menor absorção através dos tecidos foliares ou mesmo à existência de compostos, como benzoxazinonas, capazes de proporcionar reações como hidroxilação, dealquilação e até mesmo conjugação, reduzindo a atividade do herbicida (SILVA; SILVA, 2007).

Nas Figuras 1, 2 e 3 estão apresentados os resultados de massa seca dos tratamentos com e sem aplicação de herbicidas. Observa-se uma maior massa seca nas plantas mantidas em solo com 
umidade mínima de $13 \%$ (sem restrição hídrica) e uma redução de 38,5 e $55 \%$ na massa seca das plantas quando mantidas em solos com mínimos de 10 e $8 \%$ de umidade, respectivamente.

Em todos os tratamentos com aplicação de herbicidas, verificaram-se reduções da massa seca das plantas daninhas, independentemente do manejo hídrico utilizado, sendo em média de $79 \%$ nas plantas com aplicação de $100 \%$ da dose do herbicida fluazifop-p-butil (Figura 1). Com a aplicação desta mesma dose, tem-se uma diferença na massa seca de $42,9 \%$ entre plantas mantidas em solo com mínimo de 13 e $8 \%$ de umidade, corroborando os resultados de fitotoxicidade, em que as maiores porcentagens de controles foram observados em plantas sem estresse hídrico.

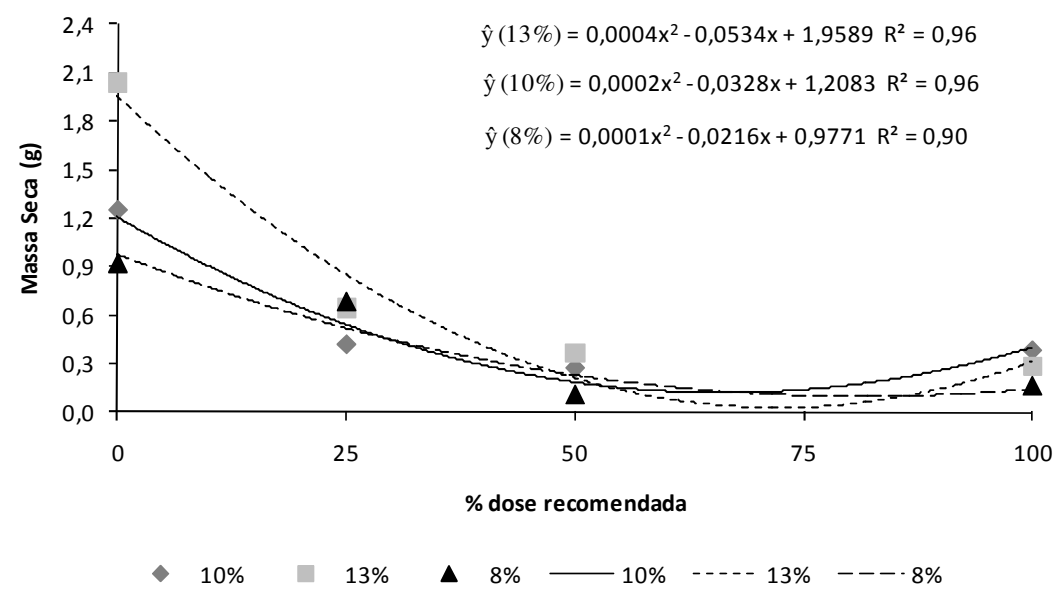

Figura 1. Massa seca de plantas de C. echinatus submetidas a diferentes manejos hídricos com aplicação do herbicida fluazifop-p-butil, em quatro doses distintas. Botucatu/SP, 2008/2009.

A massa seca das plantas sem estresse hídrico, obtida com a aplicação de $50 \%$ do herbicida haloxyfop-methyl (Figura 2) foi menor do que a das plantas mantidas em solos com mínimo de 10 e $8 \%$ de umidade, devido à maior absorção do produto pelas plantas em ótimas condições fisiológicas. Já, a massa seca das plantas submetidas à severa restrição hídrica (manejo hídrico de 8\%) manteve-se baixa devido ao menor desenvolvimento das mesmas, causado pela insuficiência de água.
Com a aplicação de $100 \%$ da dose do herbicida haloxyfop-methyl, tem-se uma redução em média de 77,4\% da massa seca das plantas em todos os manejos hídricos aplicados. Verificou-se uma menor redução da massa seca das plantas mantidas em solo com mínimo de $10 \%$ de umidade, sendo de $65 \%$, fato este, também observado nas aplicações de $100 \%$ da dose dos outros produtos.

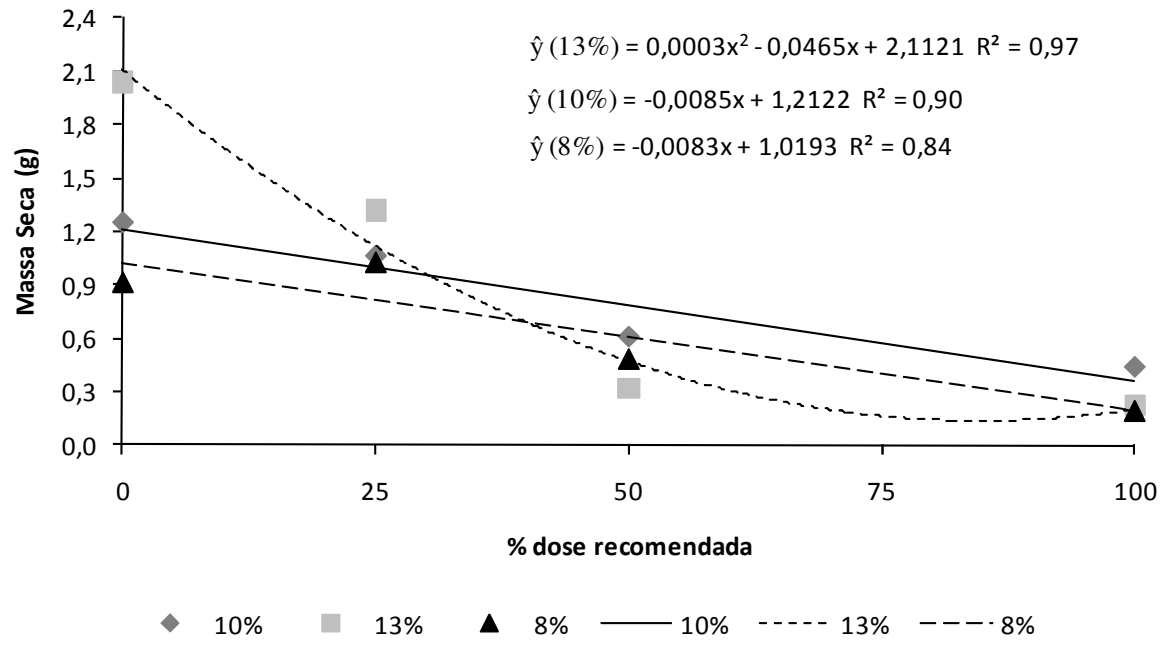

Figura 2. Massa seca de plantas de C. echinatus submetidas a diferentes manejos hídricos com aplicação do herbicida haloxyfop-methyl, em quatro doses distintas. Botucatu/SP, 2008/2009. 
O herbicida sethoxydim (Figura 3) provocou uma redução de $90 \%$ da massa seca das plantas submetidas a manejo hídrico de 13\%, 75,9 e $89 \%$ nas plantas submetidas aos manejos hídricos de 10 e $8 \%$, respectivamente. A redução da umidade mínima do solo de $13 \%$ para $8 \%$ reduziu em $45 \%$ a massa das plantas com aplicação do produto.
Com base nestes resultados pode-se inferir que as menores massas secas obtidas nas plantas sob estresse hídrico (manejo hídrico de 8\%) não esta relacionada ao efeito dos herbicidas aplicados, e sim às condições morfológicas das plantas, pois estas desenvolvem mecanismos de fuga a seca (TAIZ; ZEIGER, 2002).

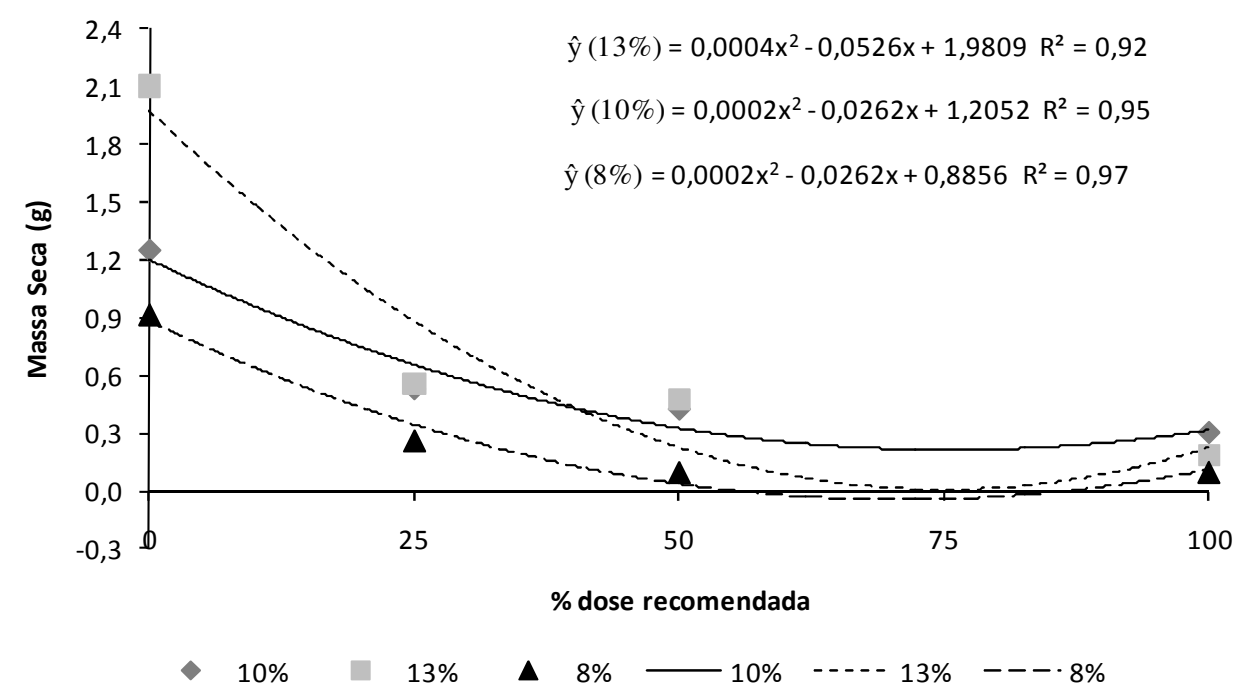

Figura 3. Massa seca de plantas de C. echinatus submetidas a diferentes manejos hídricos com aplicação do herbicida sethoxydim, em quatro doses distintas, após 28 dias. Botucatu/SP, 2008/2009.

Existem numerosos exemplos onde a absorção de herbicidas foliares pode ou não ser afetada ou reduzida quando aplicado em plantas sob estresse hídrico (ROSSI et al. 1993; WALDECKER; WYSE 1985, XIE et al. 1996). A redução da eficiência de controle dos herbicidas em plantas mantidas em solos com baixos potenciais de água pode ser explicada por diversos fatores, dentre os quais podem ser citados: quando o tecido da folha está bem hidratado, o caminhamento contínuo de água das células da folha para a cutícula facilita a absorção do herbicida através de difusão, porém em tecidos menos hidratados, esta difusão fica comprometida (KOGAN; BAYER, 1996) e, também plantas sob estresse hídrico apresentam menores taxas de crescimento e podem produzir menores quantidades de clorofila.

Além disso, períodos prolongados de seca podem causar o espessamento da folha, o aumento da densidade da cutícula, e maior pubescência da folha (SINOIT; KRAMER, 1976); tais mudanças morfológicas também poderiam diminuir a penetração dos herbicidas, resultando em redução da eficácia (MUZIK, 1976).
Em um estudo realizado por Pereira et al., (2010) com a planta daninha Urochloa plantaginea, verificou-se uma redução de 24 a $46 \%$ da massa seca em plantas submetidas à restrição hídrica em comparação com as plantas sem estresse hídrico.

\section{CONCLUSÕES}

Os herbicidas fluazifop-p-butil e sethoxydim apresentaram controles insatisfatórios, mesmo com a aplicação de $100 \%$ da dose.

A eficiência de controle de todos os herbicidas foi menor em plantas mantidas em potencial mínimo de água no solo de $-1,5 \mathrm{MPa}$ (manejo hídrico de 8\%) independente do herbicida utilizado.

O fracionamento da dose recomendada dos diferentes herbicidas em $50 \%$ em plantas mantidas em solo com tensões mínimas de $-0,03$ e -0,07 MPa não diminuiu a sua eficácia.

As massas secas das plantas sob estresse hídrico foram menos influenciadas quando da aplicação dos herbicidas. 
ABSTRACT: This project aimed to relate the efficiency of control of ACCase inhibiting herbicides applied post-emergence in Cenchrus echinatus under different soil water contents. The experiments were conducted in a greenhouse, with the application of three different herbicides (fluazifop-p-butyl, haloxyfop-methyl and sethoxydim + oil Assist) and the experimental design for each herbicide was completely randomized design with four replications, consisting a $3 \times 4$ factorial, with the combination of water management strategies $(-0.03,-0.07$ and $-1.5 \mathrm{MPa})$ and four doses of these products $(100,50,25$ and $0 \%$ of the recommended dose). Herbicide application was made at vegetative stage of 2-3 tillers. The water management strategies were initiated in the development stage of two leaves, replacing the water until the soil reaches the potential of $-0.01 \mathrm{MPa}$, when it came to severe pre-determined for each water management. The physiological parameters evaluated were: photosynthetic rate, stomatal conductance, transpiration, leaf temperature and plant dry matter. The visual assessments of phytotoxicity were performed at 7, 14, 21 and 28 days after application. The efficiency of these herbicides was influenced by soil management and water lowest in plants grown in the minimal potential of water in the soil of $-1.5 \mathrm{MPa}$. All the herbicides were unsatisfactory controls in applications late (2-3 tiller plants).

KEYWORDS: Burr grass. Chemical control. Water restriction. Weed.

\section{REFERENCIAS}

ABIT, J. M.; AL-KHATIB, K.; REGEHR, D. L.; TUINSTRA, M. R.; CLAASSEN, M. M.; GEIER, P. W.; STAHLMAN, P. W.; GORDON, B. W.; CURRIE, R. S. Differential Response of Grain Sorghum Hybrids to Foliar-Applied Mesotrione. Weed Technology, Manhattan, v. 23, n. 1, p. 28-33, 2009.

http://dx.doi.org/10.1614/WT-08-086.1

BOYDSTON, R. A. Drought stress reduces fluazifop-P activity on green foxtail (Setaria viridis). Weed Science, Lawrence, v. 40, p. 20-24, 1992.

CARVALHO, L. B.; GUZZO, C. D. Adensamento da beterraba no manejo de plantas daninhas. Planta Daninha, Viçosa, v. 26, n. 1, p. 73-82, 2008.

COBLE, H. D.; WILLIAMS, F. M.; RITTER, R. L. Common ragweed (Ambrosia artemisiifolia) interference in soybeans (Glycine max). Weed Science, Champaign, v. 29, n. 3, p. 339-348, 1981.

COBUCCI, T.; RABELO, R. R.; SILVA, W. Manejo de plantas daninhas na cultura do arroz em terras altas. Santo Antonio de Goiás: EMBRAPA Arroz e Feijão, 2001. 42 p. (Circular técnica).

CRUZ, L. S. P. et al. Herbicidas de aplicação em pós-emergência em amendoim: I. Controle de plantas daninhas e persistência no solo. Bragantia, Campinas, v. 50, p. 103-114, 1991. http://dx.doi.org/10.1590/S000687051991000100011

DAN, H. A.; DAN, L. G. M.; BARROSO, A. L. L.; OLIVEIRA JR., R. S.; ALONSO, D. G.; FINOTTI, T. R. Influência do estádio de desenvolvimento de Cenchrus echinatus na supressão imposta por atrazine. Planta Daninha, Viçosa, v. 29, n. 1, p. 179-184, 2011.

DUARTE, A. P.; SILVA, A. C.; DEUBER, R. Plantas infestantes em lavouras de milho-safrinha, sob diferentes manejos, no médio Paranapanema. Planta Daninha, Viçosa, v. 25, n. 2, p. 285-281, 2007.

GELMINI, G. A. Indicações de herbicidas para o controle de plantas daninhas na cultura do arroz de sequeiro. Campinas: CATI, 1983. 15 p. (Boletim técnico, 160).

KOGAN, M. A. Interferencia de las malezas en plantaciones y estrategias de control. In: KOGAN, M. A. Avances en manejo de malezas en producción agrícola y forestal. Santiago: Pontifícia Universidad Católica, 1992. p. 119.

KOGAN, M.; BAYER, D. E. Herbicide uptake as influenced by plant water stress. Pesticide Biochemistry and Physiology. San Diego, v. 56, p. 174-183, 1996. http://dx.doi.org/10.1006/pest.1996.0071 
MUZIK, T. J. Influence of environmental factors on toxicity to plants. In: AUDUS, L. J. Herbicides, physiology, biochemistry, and ecology. New York: Academic, 1976. v. 2, p. 204-248.

PACHECO, R. P. B.; MARINIS, G. Ciclo de vida, estruturas reprodutivas e dispersão de populações experimentais de capim-carrapicho (Cenchrus echinatus). Planta Daninha, Viçosa, v. 7, n. 1, p. 58-64, 1984.

PATTERSON, D. T. Effects of environmental stress on weed/crop interactions. Weed Science, Champaign, v. 43, n. 3, p. 483-490, 1995.

PEREIRA, M. R. R.; MARTINS, D.; SILVA, J. I. C.; RODRIGUES, A. C. P.; KLAR, A. E. Efeito de herbicidas sobre plantas de Brachiaria plantaginea submetidas a estresse hídrico. Planta Daninha, Viçosa, v. 28, n. 5, p. 1047-1058, 2010.

PEREIRA, M. R. R.; KLAR, A. E.; MARTINS, D.; SOUZA, G. S. F.; VILLALBA, J. Effect of water stress on herbicide efficiency applied to Urochloa decumbens. Ciencia e Investigación Agrária, Santiago, v. 39, n. 1, p. 211-220, 2012a. http://dx.doi.org/10.4067/S0718-16202012000100018

PEREIRA, M. R. R.; MARTINS, D.; SOUZA, G. S. F.; RODRIGUES-COSTA, A.C.P. KLAR, A. E.; Efficacy of herbicides applied in digitaria horizontalis plants under different water conditions. Planta Daninha, Viçosa, v. 30, n. 1, p. 165-172, 2012 b.

PITELLI, R. A.; PITELLI, R. L. C. M. Biologia e ecofisiologia das plantas daninhas. In: VARGAS, L.; ROMAN, E. S. (Eds.). Manual de manejo e controle de plantas daninhas. Bento Gonçalves: EMBRAPA Uva e Vinho, 2004. p. 29-56.

ROSSI, F. S.; DITOMASO, J. M.; NEAL, J. C. Fate of fenozapropethyl applied to moisture-stressed smooth crabgrass (Digitaria ischaemum). Weed Science, Lawrence, v. 41, p. 335-340, 1993.

SILVA, A. A.; SILVA, J. F. Tópicos em plantas daninhas. Viçosa, MG: Universidade Federal de Viçosa, 2007. $260 \mathrm{p}$.

SILVEIRA FILHO, A.; AQUINO, A. R. L.; SANTOS, A. B. dos. Controle de plantas daninhas na cultura do arroz de sequeiro. Goiânia: EMBRAPA, Centro Nacional de Pesquisa Arroz e Feijão, 1984. 6 p.

(Comunicado técnico, 15).

SINOIT, N.; KRAMER, P. J. Water potential and stomatal resistance of sunflower and soybean subjected to water stress during various growth stages. Plant Physiology, Bethesda, v. 58, p. 537-540, 1976.

http://dx.doi.org/10.1104/pp.58.4.537

TAIZ, L.; ZEIGER, E. Fisiologia vegetal. 3. ed. São Paulo: Artmed, 2002. 719 p.

VALLOTTON, A. D.; ABBOTT, L. B.; STERLING, T. M. African rue seedling response to herbicides applied under drought stress. Proceedings of the Western Society of Weed Science, Newark, v. 56, p. 26, 2003.

WALDECKER, M. A.; WYSE, D. L. Soil moisture effects on glyphosate absorption and translocation in common milkweed (Asclepias syriaca). Weed Science, Lawrence, v. 33, p. 299-305, 1985.

XIE, H. S. et al. Influence of water stress on absorption, translocation and phytotoxicity of fenozaprop- ethyl and imazamethabenz-methyl in Avena fatua. Weed Research, Lawrence, v. 36, p. 65-71, 1996.

http://dx.doi.org/10.1111/j.1365-3180.1996.tb01802.x 